\title{
CUIDADO À SAÚDE DE CRIANÇAS KAIOWÁ E GUARANI: NOTAS DE OBSERVAÇÃO DE CAMPO
}

\author{
HEALTH CARE OF KAIOWÁ AND GUARANI CHILDREN: FIELD \\ OBSERVATION NOTES
}

\author{
Renata Palópoli Pícoli ${ }^{++}$ \\ Rubens de Camargo Ferreira Adorno ${ }^{+}$
}

Pícoli RP, Adorno RdeCF. Cuidado à Saúde de Crianças Kaiowá e Guarani: notas de observação de campo. Rev Bras Crescimento Desenvol Hum. 2008; 18(1): 35-45.

\begin{abstract}
Resumo: Inicia-se uma discussão sobre as práticas de saúde e cuidado utilizadas pelos Kaiowá e Guarani da Terra Indígena de Caarapó no enfrentamento das doenças diarréicas na infância. Utilizou-se de uma contribuição etnográfica, através do uso da técnica da observação participante e de entrevistas aberta com moradores da comunidade. Em se tratando de uma sociedade que vivencia permanentes transformações de ordem social advindas das relações interétnicas e da sucessiva presença dos serviços de saúde, observa-se que o significado de diarréia infantil, assim como as decisões relativas à prevenção e ao seu tratamento, refletem comportamentos diferenciados e complexos. A diarréia, também conhecida como chiri, é definida através de sinais que, de certa forma, são semelhantes aos biomédicos. No entanto, nem sempre as explicações de causalidade e as formas de tratamento seguem, unicamente, a abordagem biomédica. A variedade de causas da doença diarréica entre as crianças indígenas implica na escolha do processo terapêutico, que pode ser desde a procura por um especialista tradicional, realização de chás e infusões e, ainda, procura pelos serviços de saúde. Tais explicações e formas de tratamento pressupõem a existência de um processo de negociação entre pessoas de uma mesma cultura e de culturas distintas. Neste sentido, os serviços de saúde ao tratar a criança com diarréia, devem considerar não apenas a perspectiva biomédica, mas também dialogar com a percepção e as práticas indígenas na identificação da causalidade, na definição do diagnóstico e do tratamento, sobretudo, pela coexistência destas práticas no contexto local.
\end{abstract}

Palavras-chave: Saúde infantil; diarréia infantil; etnografia; indios Kaiowá e Guarani.

\section{INTRODUÇÃO}

As práticas de saúde utilizadas pelos Kaiowá e Guarani* no enfrentamento dos agravos infantis, sobretudo, em relação às doenças diar- réicas estão descritas neste trabalho buscando compreender as complexas relações que se estabelecem entre sistemas culturais distintos, medicina indígena e biomedicina.

A nosso ver, há dificuldades em compre-

\footnotetext{
Departamento de Saúde Materno Infantil/Faculdade de Saúde Pública/Universidade de São Paulo. Av: Dr. Arnaldo, 715, Bairro: Cerqueira César

${ }^{++}$R: Senador Ponce, 1435 bloco 1 apto 23, Bairro: Jardim Paulista, Cep: 79050-220 Campo Grande/MS - E-mail: rpicoli@usp.br

* Os índios Guarani do Estado de Mato Grosso do Sul, estão representados pelas populações Kaiowá e Ñandeva, sendo que esta última se reconhece e é reconhecida por Guarani; será, portanto, tratada por esta denominação. Embora em menor número e historicamente localizados ao sul da bacia do Rio Iguatemi, os Guarani estão presentes em várias terras indígenas Kaiowá. Desta forma, utilizamos, neste texto, a designação Kaiowá e Guarani, quando fizermos menção à população da Terra Indígena de Caarapó.
} 
ender essa distinção, pois amplamente se toma e se pensa que a questão da saúde se resolve a partir do acesso aos serviços médicos. Não é objetivo desse artigo aprofundar essa discussão mas tomá-la como referência.

Ao considerá-las como sistemas culturais, utilizamos à teoria de cultura definida por Turner ${ }^{1}$ como sendo um sistema de símbolos que define e produz a si mesmo enquanto entidade social em relação a sua situação histórica em transformação.

Neste sentido, apresenta-se uma perspectiva de leitura das práticas de saúde e cuidado infantil não como práticas fixas e fechadas, mas sim como um conjunto de ações que são redefinidas e negociadas, continuamente, na interação social.

Esta discussão passa pelo conceito de negociação, que segundo $B$ habha ${ }^{2}$ deve ser utilizado para buscar superar as visões dualistas, que opõem, simplesmente, centro-periferia, rico-pobre, chamando a atenção para as estruturas de interação presentes entre ambos, ao articular elementos antagônicos e opostos, porém, sem a pretensão da sua superação dialética.

Desta forma, foi na Terra Indígena de Caarapó, Estado de Mato Grosso do Sul, onde vivem aproximadamente 4.224 pessoas do grupo étnico Kaiowá e Guarani, que a problemática do estudo buscou elucidar a complexidade das práticas de saúde utilizadas nos casos de diarréia infantil. A população infantil na faixa etária de zero a cinco anos, no período estudado, era de aproximadamente 800 crianças.

Antes, porém, de discutir as práticas de saúde infantil, apresenta-se, brevemente, o contexto histórico e social da Terra Indígena de $\mathrm{Ca}-$ arapó, por entender que as relações interpessoais e interétnicas que se estabelece(ra)m, ao longo de décadas de contato, com a sociedade nãoindígena têm sua importância na redefinição da organização social, assim como na ampliação de seu sistema cultural de saúde.

\section{Breve descrição da Terra Indígena Caarapó}

A Terra Indígena (TI) de Caarapó com território de 3.594 hectares, está localizada à aproximadamente 14 quilômetros do município de Caarapó. Foi à terceira área demarcada pelo extinto Serviço de Proteção aos Índios - SPI, durante o período de 1915 a 1928. Neste período foram demarcadas oito reservas - pequenas extensões de terra, para usufruto dos Kaiowá e Guarani - perfazendo um total de 18.124 hectares, com o objetivo de confinar os núcleos indígenas, liberando o restante do território para a colonização.

Percorrendo a estrada que dá acesso a TI de Caarapó, o que se observa é uma vegetação gramínea - chamada braquearia, típica de fazendas de criação de gado. Ao entrarmos em território indígena é possível perceber uma mudança na vegetação, com árvores esparsas que algumas vezes acompanham a distribuição das casas. No entanto, observa-se um comprometimento crescente dos recursos ambientais pela expansão da braquearia em terras indígenas.

O comprometimento dos recursos naturais e, consequentemente, de suas alternativas econômicas próprias é descrito por Grünberg ${ }^{3}$, Brand $^{4}$ e Pereira ${ }^{5}$ ao destacarem que o avanço das gramíneas sobre a roça de cultivo dos Guarani não se reflete apenas no impacto sobre a economia indígena mas, sobretudo, na organização social e religiosa, já que os rituais de plantio representam momentos importantes, que garantem o equilíbrio da terra e da produção pelas forças cósmicas.

Percorrendo aproximadamente quatro quilômetros pela TI de Caarapó, chegamos à região central, onde está localizada a Escola Municipal Indígena Ñandejara, o Posto da Fundação Nacional do Índio (FUNAI) e o Posto de Saúde Zacarias Marques. Próximo a estes estabelecimentos moram as parentelas de maior prestígio interno dentro da reserva indígena..

Como destacado pela literatura produzida sobre este povo, a parentela ${ }^{5}$, também conhecida como família extensa ${ }^{6}$, representa a base da sua organização social. Seus integrantes devem seguir a orientação de um cabeça da parentela $h i$ ' $u$ - e estabelecer entre si, laços de solidariedade política, econômica e religiosa, que garantam o equilíbrio de sua vida social.

Em linhas gerais, a parentela é represen- 
tada, portanto, por um círculo de pessoas relacionadas por vínculos parentais, tendo a predileção por determinados parentes identificados por grupo de residência, de atuação econômica e política ${ }^{5}$.

De maneira geral, as redes de alianças, atualmente, seguem a lógica da atuação política, na qual se observa a diminuição relativa dos aspectos de parentesco de consangüinidade e uma crescente importância à questão política, pelo prestígio do líder da parentela.

Observa-se, contudo, que estas alianças são cercadas de tensões e negociações constantes. Por exemplo, ao oferecer ajuda a um integrante de sua parentela, o líder exige, implicitamente, apoio político e, ao mesmo tempo, fortalece seu prestígio.

A observação de campo levantou aspectos importantes sobre esta questão. As pessoas que não conseguem alianças com parentelas de prestígio, passam a vivenciar um processo de marginalização interna que implica, na maioria das vezes, em problemas sociais, econômicos e de saúde, por terem dificuldades de resolvê-los individualmente.

Em outras palavras, a tentativa de se adaptarem às mudanças sociais, que envolvem questões históricas e econômicas, ao longo de décadas de contato, criou problemas de diferentes naturezas, como, a adoção de um processo de atuação política interna que não consegue mais responder aos interesses coletivos.

Essas são, certamente, questões relevantes para entender a situação de saúde de crianças indígenas, pois num contexto de tensões e negociações constantes entre as parentelas e destas com a sociedade não-indígena aqui, especialmente, a atuação dos órgãos governamentais, que ao difundirem um modelo de poder coercitivo e individualizado, contrariando as normas de reciprocidade, amplia os conflitos e a oposição de parentelas em assuntos de ordem política da comunidade. Estamos, pois, diante de uma sociedade que tem apresentado contrastes na sua constituição social, mais ou menos profundos.

Vê-se, portanto, que seu constante movimento e redefinições trazem implicações no campo das relações sociais e situações de crise e comportamentos que passam a desproteger e precarizar determinados grupos de parentesco. Tal complexidade de relações é representada e reproduzida nos problemas sociais e de saúde infantil emergentes.

\section{Breve descrição da saúde indígena: macro e micro-contexto}

A gestão da saúde do povo Kaiowá e Guarani está sob a responsabilidade do Distrito Sanitário Especial Indígena (DSEI) de Mato Grosso do Sul. Sua implantação ocorreu em 1999, com a Lei 9.836 que instituiu a implantação do subsistema de atenção indígena, baseado em distritos sanitários, no âmbito do Sistema Único de Saúde (SUS) ${ }^{7}$.

O DSEI é responsável por desenvolver programas específicos de atenção básica em áreas indígenas, que visem à prevenção e o controle de agravos à saúde.

A organização dos serviços de saúde segue uma hierarquização, os Postos de Saúde, localizados nas terras indígenas, devem ser a primeira referência, realizando ações de atenção básica. O Pólo-Base, como instância local, deve monitorar as ações de atenção básica, oferecendo o suporte necessário nos atendimentos nas terras indígenas.

No que se refere à assistência à saúde na TI de Caarapó, os atendimentos são realizados por duas equipes multidisciplinares de saúde indígena (dois médicos, duas enfermeiras, três auxiliares de enfermagem, dois odontólogos, uma nutricionista, nove agentes indígenas de saúde e motoristas) nos Postos de Saúde Zacarias Marques e Ñanderu João Paulo, este último inaugurado em setembro de 2006.

No período matutino, o profissional médico atende em média 20 consultas, priorizando o atendimento às crianças. No período vespertino, realiza atendimentos domiciliares e só recentemente um médico pediatra passou a realizar atendimentos no Posto de Saúde Zacarias Marques, uma vez por semana.

Os serviços de média e alta complexidade devem ser referenciados para a rede de serviços do SUS. O Pronto Atendimento Municipal 
de Caarapó é referência para o atendimento ambulatorial (ginecologia, clínica médica e pediatria) e o Hospital São Matheus é referência hospitalar, enquanto os casos que demandam atendimentos de alta complexidade são referenciados para o Hospital Universitário e o Hospital Porta da Esperança, ambos localizados no município de Dourados. Este último está sob a gestão da Organização Não-Governamental Missão Evangélica Caiua, que realiza atendimento às crianças indígenas desnutridas.

No âmbito legal, em nosso entender, os principais avanços na definição de um modelo de atenção diferenciada foram propostos pela Política Nacional de Saúde Indígena ${ }^{8}$, porém, ao mesmo tempo, a implementação deste modelo esbarra na fragilidade dos serviços de saúde que, ainda hoje, transferem e reproduzem na TI de Caarapó, em larga medida, ações de saúde infantil desenvolvidas no entorno regional. Esta verticalização se contrapõe à proposta da Política Nacional de Saúde Indígena.

No que tange ao abastecimento de água, a TI de Caarapó conta com uma rede a partir de dois poços artesianos, de onde a água é bombeada para duas caixas d'água e, então, segue através de encanamentos para várias áreas da Terra Indígena de Caarapó. Embora, a rede de abastecimento esteja em funcionamento, é comum a restrição de água em alguns períodos do dia em algumas das áreas desta TI.

Para contornar esse problema, algumas famílias armazenam água em baldes e panelas com ou sem tampa, enquanto outras utilizam água de poço artesanal. Estes fatores, certamente, estão relacionados à ocorrência de diarréia entre as crianças. Além deste fator, deve-se considerar também as precárias condições de saneamento, tornam-se agravantes à saúde infantil contribuindo para a recorrência de doenças diarréias entre as crianças.

A situação sanitária observada nesta comunidade assemelha-se a outras descritas em diversos estudos ${ }^{9,10}$, com populações indígenas de diferentes regiões, onde também foram observadas as precárias condições de saneamento.

Para realizar o trabalho de manutenção da rede de abastecimento e orientações sobre como aproveitar melhor a água. a TI conta com dois agentes indígenas de saneamento-AISAN. No entanto, suas ações estavam restritas à manutenção da rede, visto que até o período de realização do trabalho de campo (novembro de 2006), não haviam recebido capacitação para atuarem junto às famílias.

\section{MÉTODO}

Para o registro da coleta de dados, buscamos realizar uma aproximação a partir da contribuição etnográfica, através do uso da técnica da observação participante e de entrevistas abertas com moradores da TI de Caarapó. Em função de nossa formação essa experiência resultou em um aprendizado, pois a todo momento voltávamos a procurar ou a tomar como referência condutas na observação nas quais ficava evidente a interferência de nossos valores ou de nossos critérios técnicos avaliativos.

Foi a partir da contribuição do olhar etnográfico que pudemos relativizar a idéia de realizar entrevistas individuais ou aplicar roteiros de entrevistas. A experiência de campo foi, aos poucos, nos mostrando os limites dessas técnicas, que vem sendo consideradas "qualitativas". O exercício do campo foi nos levando a refletir sobre a realização de perguntas e nos impondo a observação e a vivência do diálogo mediado pelo grupo de parentesco.

A escolha da TI de Caarapó como local de pesquisa foi resultado de desdobramentos de trabalhos anteriores ${ }^{11,12,13}$.

A pesquisa de campo foi realizada em viagens de 3 a 5 dias de duração, em intervalos de aproximadamente 15 dias, nos meses de julho a novembro de 2006, após obtenção da autorização prévia das lideranças da Terra Indígena de Caarapó e aprovação pelo Comitê de Ética em Pesquisa da Faculdade de Saúde Pública da Universidade de São Paulo e pela Comissão Nacional de Ética em Pesquisa.

O primeiro momento da pesquisa caracterizou-se por contatos com pessoas já conhecidas, que no decorrer do trabalho se tornaram nossos colaboradores, prioritariamente professores que, atualmente, são reconhecidos pela co- 
munidade como lideranças locais. Esta legitimação decorre da importante atuação como mediadores do diálogo intercultural, nos últimos anos.

Para selecionar as parentelas participantes do estudo, procedeu-se, primeiramente, conforme as recomendações sugeridas pelos colaboradores, ainda na forma de identificação de possíveis participantes do estudo. A identificação, pelos colaboradores, seguiu alguns critérios por eles elencados: grupos que residem há muitos anos na TI Caarapó e que, de certa maneira, detêm os conhecimentos que se pretendia observar. Neste sentido, a identificação contou com mecanismos próprios por eles definidos como escolhas confiáveis, isto é, conhecidas e, de certo modo, também, sob controle deles próprios.

Mesmo tendo, a priori, definido as parentelas, optamos por validar os critérios acima estabelecidos e elencar outros, realizando visitas a algumas parentelas, procurando selecionar grupos que pudessem refletir as múltiplas situações de saúde infantil.

O estudo procurou identificar práticas de saúde infantil em diferentes idades do ciclo de vida da pessoa Kaiowá e Guarani, no entanto, as observações foram registradas entre as crianças com idade até seis anos, pela sua convivência contínua com as pessoas de seu grupo familiar, enquanto para as crianças com idade acima de seis anos as observações foram mais esporádicas, já que neste período de suas vidas começam a freqüentar a escola.

Neste sentido, procuramos delimitar a observação das práticas de saúde e cuidado infantil, realizando visitas periódicas a quatro parentelas $\left(t e^{\prime} y i\right)$. As primeiras visitas aconteceram em companhia dos agentes indígenas de saúde, buscando uma maior aproximação, a fim de estabelecer um relacionamento caracterizado pela confiança mútua, como explicado por Thomp$\operatorname{son}^{14}$, ao afirmar que um relacionamento de confiança e visitas sucessivas pode favorecer o registro de dados mais fidedignos. É importante enfatizar que no primeiro contato havia sempre a menção da pessoa que nos indicava, o que permitiu, de certa forma, uma boa recepção e disponibilidade das famílias selecionadas.

Para a realização da entrevista foi previa- mente elaborado um roteiro, para aplicação, no entanto, esta estratégia mostrou-se inadequada. Os relatos, em grande parte, se iniciavam contando suas histórias de vida ou experiências vividas por seus familiares, o que pode ser considerado ou tomado como uma narrativa a ser interpretada e não apenas uma resposta a uma questão. Quando necessário foram realizadas perguntas, objetivando esclarecer detalhes elucidativos sobre essas narrativas mencionadas pelos informantes.

As entrevistas realizadas no espaço familiar, na maioria das vezes, aconteceram em grupo, observando-se uma relação mais descontraída e de informalidade. Isto decorre, em parte, pela convivência diária de mulheres e de crianças num mesmo espaço, geralmente na residência do líder de seu grupo e, ainda, pela redefinição da posição da mulher.

Se no passado a mulher indígena administrava a economia doméstica, que incluía a casa, a roça e o cuidado com o bem-estar de suas crianças, no presente, a diminuição dos espaços para cultivar suas roças aliado à intensificação das políticas governamentais de distribuição mensal de cestas de alimentos tem rompido os padrões tradicionais de ocupação da mulher, enfraquecendo a subsistência e aumentando a dependência de programas sociais.

Nos primeiros contatos, as pessoas reproduziam para nós o repertório indicado pelo tratamento de orientação biomédica. Este comportamento talvez tenha uma explicação, porque as práticas de saúde e de cuidado utilizadas acontecem no espaço particular de sua residência e de sua parentela, e, portanto, falar sobre isso com a pesquisadora demanda tempo, até que se estabeleça um relacionamento e se conheçam quais as suas intenções. $\mathrm{E}$, ainda, por que a princípio viam a pesquisadora como representante do discurso biomédico.

As informações principais e as frases essenciais, assim como, as observações sobre o contexto e as impressões da pesquisadora sobre o conteúdo da narrativa foram anotados no diário de campo, durante ou imediatamente após cada entrevista ou conversa informal.

Durante o trabalho de campo, utilizou-se 
o pátio da Escola Municipal Indígena Ñandeja$r a$ para realizar os registros. No decorrer da pesquisa, esse espaço tornou-se um lugar estratégico, por facilitar a observação dos acontecimentos da Escola, do Posto de Saúde Zacarias Marques e do Posto Indígena da FUNAI, todos localizados na área central da Terra Indígena, onde o fluxo de pessoas é constante. A pesquisadora também era motivo de observação das pessoas, tanto que algumas se aproximavam para contar algum fato ou ainda para perguntar o que se anotava no caderno de campo.

As maiores limitações encontradas em relação à observação se deram em relação à participação da parentela na utilização das formas de cuidado à criança com problemas de saúde, visto que a presença da pesquisadora alterava o cotidiano. As pessoas se preocupavam em preparar tereré - bebida à base de erva mate - para servir à pesquisadora, sentavam-se à sombra de uma árvore e conversavam durante horas.

\section{O sentido de diarréia e as práticas de saúde utilizadas no tratamento para os Kaiowá e Guarani}

A identificação das práticas de saúde e cuidado à criança indígena com diarréia não foi tarefa fácil. Em se tratando de uma sociedade que vivencia permanentes transformações de ordem social, advindas das relações interétnicas, assim como a sucessiva presença dos serviços de saúde, observa-se que a doença é percebida diferentemente pelas pessoas. Isto pode ser justificado, em parte, pela constante negociação entre pessoas de sua rede de parentesco e destas com os serviços oficiais de saúde.

Levando-se em conta estes aspectos, parece evidente que o significado de diarréia infantil, assim como as decisões relativas à prevenção e ao seu tratamento, refletem comportamentos diferenciados e complexos.

Inicialmente, porém, é importante salientar que a Organização Mundial de Saúde ${ }^{15}$, em 1984, elaborou uma definição para diarréia como forma de identificar os seus sinais: "três ou mais evacuações num dia, com fezes de consistência mole ou líquida ou alguma evacuação com san- gue ou muco misturado com fezes, podendo conduzir a um quadro de desidratação, que se caracteriza por perda excessiva de água corporal através das fezes, vômito, urina, transpiração e outras perdas menos sensíveis".

Certamente, a definição de diarréia pela $\mathrm{WHO}^{15}$ facilita o diagnóstico e o tratamento na área biomédica, no entanto, mostra-se insuficiente para descrever os casos de diarréia, visto que esta doença tem distintas abordagens no contexto sociocultural de cada sociedade.

Para ilustrar isso, tomemos como exemplo a diarréia infantil, também conhecida como chiri, entre os Kaiowá e Guarani. Apesar da identificação dos sinais da diarréia ser, de certa forma, semelhante aos biomédicos, descrevendo-os como fezes moles ou líquidas evacuadas várias vezes ao dia, nem sempre a explicação da causalidade e as formas de tratamento seguem, unicamente, a abordagem biomédica.

Tais explicações e práticas de tratamento pressupõem a existência de um processo de negociação entre pessoas de uma mesma cultura e de culturas distintas.

Todavia, o pressuposto sobre a viabilidade deste processo de negociação entre culturas distintas na práxis, esbarra nos entraves do diálogo interétnico, pelo discurso hegemônico da biomedicina. Como destaca Roberto Cardoso de Oliveira ${ }^{16} \mathrm{o}$ comprometimento do diálogo está na relação de poder, a saber, em se tratando das relações entre índio e não-índio, a hegemonia das regras institucionalizadas do discurso do pólo dominante sobre o pólo dominado.

Este autor destaca, sobretudo, a necessidade de o diálogo ser num plano simétrico entre interlocutores - indivíduos ou grupos - e manter um diálogo livre, sem a dominação de um interlocutor sobre o outro. Devendo, portanto ocorrer num espaço substancialmente democrático ou pelo menos democratizável.

Nessa direção, ainda em relação à construção do diálogo interétnico, é cada vez mais premente a necessidade de considerar os serviços de saúde como espaços possíveis para a efetivação desse diálogo.

Embora reconheçamos esta necessidade, sabemos que é no mínimo altamente complexo o 
seu estabelecimento, pelas recorrentes dificuldades em legitimar as diferenças culturais.

Estabelecido o enfoque do processo de negociação e suas fragilidades, ainda, existentes pelas relações de poder radicalmente assimétricas. Recorremos às observações de campo para apontar que as explicações para a ocorrência de diarréia, sua gravidade e causalidade implicam em formas de ressignificação de suas práticas de saúde, assim como na articulação da biomedicina com o sistema de saúde indígena.

As longas conversas permitiram-nos compreender que a explicação etiológica da diarréia, frequentemente, comanda a sua representação terapêutica. Assim sendo, para intervir de forma eficaz acredita-se que é preciso conhecer de início a causa da doença ${ }^{17}$.

A diarréia infantil entre os Kaiowá e Guarani, pode ser causada por coalho virado, seu termo na língua guarani é kamby ryru jer. Nestes casos, a identificação dos fatores que definem o coalho virado é variada. A explicação mais comum refere-se a um movimento brusco que a criança faz logo após a refeição, por exemplo, pular de uma árvore. Ou ainda, quando a criança " $c o$ meu alguma coisa que fez mal", seu termo na língua guarani é "tupichua". No entanto, não foi identificado nenhum alimento específico que explicasse a ocorrência da doença, não permitindo, portanto, uma análise mais aprofundada.

Além dessa causa, a quebra dos laços maternos representada pelo desmame precoce foi mencionada como responsável por acarretar diarréia entre as crianças. Nestes casos, percebe-se a importância do leite materno como um importante fator no cuidado que contribui para a formação da criança indígena. Neste sentido, a interrupção do aleitamento materno, antes do período de desmame, que para a mulher Kaiowá e Guarani é apenas quando engravida novamente, é a causa de agravos à saúde da criança:

"minha filha parou de tomar leite [materno] tem dois meses, pode ter ficado um resto de leite no seu corpo [estômago] que qualha" (mulher).

Vê-se, claramente, neste caso, que a cau- salidade da doença diarréia não implica necessariamente num tempo próximo. Aqui a questão 'tempo' relacionada à causalidade da doença assume outras dimensões e, portanto, não pode ser explicada por um tempo próximo ou imediato à identificação dos sinais da doença. Implica, igualmente, reconhecer, como descrito por Laplantine ${ }^{17}$, que a identificação dos sinais da doença nem sempre evoca uma causalidade próxima.

Outra causa relacionada à diarréia por $c o$ alho virado é o desrespeito as "regras de evitação" pelos pais, principalmente no primeiro ano de vida da criança. Por exemplo, a quebra da dieta alimentar da mãe ou mesmo a prática de trabalhos pesados pelo homem. Embora esta explicação de causalidade tenha sido mencionada, percebe-se que sua prática, atualmente, segue uma outra lógica, pela complexa realidade social.

Na medida em que a realidade social é alterada, criam-se também novas práticas de saúde infantil, sem, no entanto, perder o sentido do cuidado à saúde segundo a perspectiva indígena. Como explica o antropólogo Marshall Sahlins ${ }^{18}$ "a tradição consiste aqui nos modos distintos como se dá a transformação: a transformação é necessariamente adaptada ao esquema cultural existente" (p. 62). O autor propõe que se reflita sobre a complexidade dos arranjos que os povos utilizam para sobreviver.

Outra questão citada inúmeras vezes como sendo causalidade de doença diarréica foram as precárias condições de abastecimento de água e de destino dos dejetos humanos.

Neste sentido, parece verdadeiro afirmar que os Kaiowá e Guarani reconhecem as implicações das precárias condições sanitárias sobre o estado de saúde da criança, desencadeando doenças diarréicas.

Outros fatores, embora mais amplos e subjacentes que contribuem para manter o perfil epidemiológico desta população, com destaque para a diarréia infantil como uma dos principais morbidades estão os aspectos históricos, econômicos e sociais que, certamente, afetaram as condições gerais de vida deste grupo.

As explicações sobre a causalidade da doença diarréica, descritas anteriormente, mostram a sua complexidade que, neste caso, é ine- 
rente ao processo social e ambiental vivenciado por este povo. E que, portanto, reduzi-las a uma única causalidade, como fazem os serviços oficiais de saúde, estaríamos negando o processo de negociação e ressignificação das causalidades para responder à sua realidade atual.

É importante ressaltar que este processo de negociação entre sujeitos de uma mesma cultura ou de culturas distintas é algumas vezes acompanhado de tensões e conflitos.

Sobre esta situação de conflito entre sujeitos de uma mesma cultura é mais comum entre diferentes gerações:

"[a mãe jovem] perde tempo no Posto [de Saúde] tem que procurá remédio do mato [para tratar a diarréia da criança]" (mulher).

Sobre este aspecto a antropóloga Jean Langdon ${ }^{19}$ explica que "diferentes diagnósticos de uma mesma doença aumentam consideravelmente quando os participantes do processo possuem diferentes conhecimentos, experiências e interesses em relação ao caso em pauta. Entre os membros de um grupo, nem todos possuem o mesmo conhecimento, devido a vários fatores: idade, sexo, papel social (i.e. pessoas leigas, especialista em cura, pajé) e também redes sociais e de alianças com outros" (p. 122).

Estas considerações reiteram as observações de campo sobre a determinação do diagnóstico e do tratamento da diarréia infantil. Quanto maior for o número de pessoas envolvidas (mulheres de uma mesma rede de parentesco, agentes indígenas de saúde, caciques e profissionais de saúde) maiores são as possibilidades de escolhas de recursos terapêuticos diferenciados, podendo (ou não) serem acompanhados de conflitos.

Antes de passarmos à discussão do itinerário terapêutico nos casos de diarréia infantil, faz-se necessário defini-lo. Para Buchillet ${ }^{20}$, itinerário terapêutico é "um conjunto de processos implicados na busca de um tratamento desde a constatação de uma desordem, passando por todas as etapas institucionais (ou não) onde podem se atualizar diferentes interpretações (paciente, família, comunidade, categorias de curadores etc.) e curas" (p. 28).

Nesta acepção, entendemos que a escolha pela forma de tratamento, como observado na pesquisa de campo, envolve aspectos subjetivos e culturais em torno da percepção da causalidade da doença e da eficácia de determinado recurso terapêutico na busca pela cura.

Neste sentido, para um mesmo evento de diarréia podem ser utilizados diferentes recursos: a procura por especialista tradicional, a utilização de chás ou infusões feitos à base de plantas medicinais, a procura pelo pastor para orar pela criança, a realização de massagem no corpo (barriga e pernas) da criança, neste caso pode ser feita por uma mulher de idade, que participa dos cuidados e dos ensinamentos à criança e, ainda, a procura pelo serviço oficial de saúde.

É importante enfatizar que alguns chás, feitos à base de plantas medicinais, devem ser acompanhados de reza, para que todo o potencial terapêutico da planta seja utilizado. Como mencionado por Laplantine ${ }^{17}$ a utilização de plantas medicinais como recurso está longe de poder ser explicada pelas propriedades estritamente médicas que lhes são atribuídas.

É, pois, possível dizer que os chás são elementos importantes de seu sistema cultural pela inter-relação com os elementos religiosos. Não devendo, portanto, ser tomados como fragmentos de uma tradição.

Embora a procura pelo especialista em cura, cacique ñanderu*, tenha sido referida pelos indígenas, percebe-se, no entanto, que as práticas de cura realizadas por este tipo de especialista, atualmente, são inexistentes, pelo fato dos indígenas não reconhecerem a figura deste especialista em seu meio

"ñanderu era a pessoa que tinha poderes sobrenaturais [...] tinha o poder da re-

A expressão ñanderu inclui todas as pessoas iniciadas nas práticas rituais, também reconhecido como xamã. É uma pessoa poderosa, que vive distanciada do convívio cotidiano. Caracteriza-se por manter contato freqüente e sistemático com o mundo dos deuses, espíritos e antepassados, por isso é reconhecido como aquele que conhece tudo porque tudo vê5. 
velação, de saber os males das pessoas, mas hoje em dia, não existe mais essa pessoa" (professor indígena).

Dada a inexistência do cacique ñande$r u$, algumas famílias recorrem ao rezador, outra categoria de especialista, no tratamento da diarréia infantil:

"quando meu filho tinha quatro meses de idade precisou ficar oito dias internado por diarréia. Ele só melhorou quando levei no rezador, que rezou por três sextas-feiras consecutivas e fez um remédio caseiro" (agente indígena de saúde).

Percebe-se, no entanto, que esta prática comum há alguns anos tende a esmaecer-se diante da realidade atual, pela perda de prestígio e seriedade dos caciques. Atualmente, muitos caciques são classificados, pelas atuais gerações, como cacique ngua' (caciques falsos). Esta representação decorre, em parte, pela atuação das igrejas presbiterianas e neopentecostais, na TI de Caarapó, no sentido de desencorajar a procura pelo cacique.

Outra questão importante que, certamente, fragiliza a atuação do cacique é a crescente presença dos serviços de saúde que, ao se colocarem como representantes do campo da saúde restringem os tratamentos ao horizonte biomédico.

Nesse aspecto também determinadas técnicas introduzidas na atenção primária pelos agentes de saúde acabam ganhando uma legitimidade própria como é o caso da terapia de reidratação oral segundo recomendações do Ministério da Saúde ${ }^{21}$ - utilizada por esse serviço como medida de prevenção da desidratação evitando as mortes e os agravos à saúde das crianças indígenas por doenças diarréicas.

A aceitação do soro de reidratação oral (SRO) mostrou-se positiva entre as famílias visitadas, talvez porque ganhassem uma semelhança à utilização de chás, ou por uma atribuição de elemento de substância a mistura de sal, açúcar e água. Essa aceitação pode ser evidenciada pelo modo diferenciado que algumas famílias usam a reidratação caseira a despeito da orientação dos agentes e do serviço de saúde. Esta diferenciação está no oferecimento diário de SRO para as crianças, mesmo na ausência de algum sinal de diarréia.

Este comportamento, muito provavelmente esteja associado aos significados atribuídos ao soro de reidratação oral no restabelecimento da saúde da criança. Compreendido, sobretudo, por uma representação terapêutica similar a determinados tipos de chás de ação preventiva de agravos à saúde das crianças. Para ilustrar isso, utilizamos as explicações de Laplantine ${ }^{17}$ : uma representação terapêutica pode ser utilizada em alguns momentos para razões essencialmente preventivas e em outros momentos como uma ação curativa.

A argumentação desenvolvida no parágrafo anterior esclarece a importância de reconhecer que a procura pelos serviços de saúde, nos casos de diarréia infantil investigados, representa uma prática complementar e não substitutiva ao sistema de saúde indígena. Neste sentido, a interação de diferentes percepções sobre o significado de diarréia infantil e as escolhas sobre o processo terapêutico dá origem a uma outra realidade, caracterizada pela existência simultânea de formas de terapias ou 'medicinas' que coexistem no contexto local ${ }^{22}$.

Neste sentido, as discussões apresentadas acima destacam a necessidade de compreender que esta prática complementar não é a de simples adição de dois conhecimentos, biomedicina e medicina indígena. É, sobretudo, uma apropriação e ressignificação de tais práticas segundo realidade simbólica deste povo.

\section{CONSIDERAÇÕES FINAIS}

A partir da discussão realizada, algumas considerações podem ser feitas, sobretudo, em relação ao entendimento de que as práticas de saúde utilizadas no tratamento dos casos de diarréia infantil permanecem ativas, constatandose, também, a redefinição e a atualização de algumas práticas, mediante negociação com outros sistemas culturais (biomedicina, entre outros). Não obstante, os arranjos realizados demonstram, 
sobretudo, que os Kaiowá e Guarani continuam distinguindo-se da sociedade não-indígena pelos significados que as técnicas e os procedimentos biomédicos assumem.

Neste sentido, os serviços de saúde, ao tratar a criança com diarréia, devem considerar não apenas a perspectiva biomédica, mas, também, dialogar e interagir com as percepções indígenas na identificação da causalidade, dos sinais, da definição do diagnóstico e do tratamen- to, sobretudo, pela coexistência destas práticas no contexto local.

A situação de saúde infantil, com destaque para a ocorrência de diarréia, representa as adversidades de condições de vida desta população, sobretudo, relacionadas aos aspectos de saneamento, de acesso aos serviços de saúde, assim como as questões históricas, econômicas e sociais vivenciadas durante décadas de contato com a sociedade não-indígena.

\begin{abstract}
In this article, we start a discussion on health and care practices used by the Kaiowá and Guarani from Caarapó Indian Reserve in coping with diarrhea diseases in childhood. This ethnographical study was carried out through the use of the participant observation technique and open interviews with the community's inhabitants. As it is a society that experiences permanent social transformations deriving from interethnic relations and from the successive presence of the health services, it is observed that the meaning of infantile diarrhea, as well as the decisions related to prevention and treatment, reflect different and complex behaviors. Diarrhea, also known as chiri, is defined through signals that, in a certain way, are similar to the biomedical ones. However, the explanations of causes and the forms of treatment sometimes do not follow the biomedical approach. The variety of causes of diarrhea disease among Indian children implies the choice of the therapeutic process, which can be the search for a traditional specialist, the preparation of teas and infusions and the search for the health services. Such explanations and forms of treatment presuppose the existence of a negotiation process between people from the same culture and from distinct cultures. Thus, the health services, when treating the child with diarrhea, must not only consider the biomedical perspective, but they should also interact with the Indian perception and practices, in order to identify the causes and to define the diagnosis and treatment, mainly because of the coexistence of these practices in the local context.
\end{abstract}

Keywords: Children's health; infantile diarrhea; ethnography; Kaiowá and Guarani indians.

\section{REFERÊNCIAS}

1. Turner V. The ritual process. Chicago: Aldine Publishing; 1966.

2. Bhabha HK. O local da cultura. Belo Horizonte: UFMG; 1998.

3. Grünberg FP. Reflexões sobre a situação dos Guarani no Mato Grosso do Sul, Brasil. Brasília:EAG-CTI. 2000; 1-21.

4. Brand A. Biodiversidade, sócio-diversidade e desenvolvimento: os Kaiowá e Guarani no Estado de Mato Grosso do Sul. In: Costa RB (org). Fragmentação florestal e alternativas de desenvolvimento rural na região Centro-Oeste. Campo Grande: UCDB; 2003. p.175-204.

5. Pereira LM. Imagens Kaiowá do sistema social e seu entorno [tese]. São Paulo: Faculdade de Filosofia, Letras e Ciências Humanas da
Universidade de São Paulo; 2004.

6. Grünberg FP. Guarani: algumas notas. Brasília: EAG-CTI. 2004; p. 1-8.

7. Ministério da Saúde. Lei n. 9836, de 23 de setembro de 1999. Regulamentação do Subsistema de Atenção à Saúde Indígena Brasília: Ministério da Saúde; 1999.

8. Fundação Nacional de Saúde. Política Nacional de Atenção a Saúde Indígena. Brasília: Fundação Nacional de Saúde; 2002.

9. Leite MS, Gugelmin SA, Santos RV, Coimbra Jr CEA. Perfis de saúde indígena, tendências nacionais e contextos locais: reflexões a partir do caso Xavánte, Mato Grosso. In: Coimbra Jr CEA, Santos RV, Escobar AL, organizadores. Epidemiologia e saúde dos povos indígenas no Brasil. Rio de Janeiro: Fiocruz/Abrasco; 2003. p.105-26. 
10. Ribas DLB, Sganzerla A, Zorzatto JR, Philippi ST. Nutrição e saúde infantil em uma comunidade indígena Teréna, Mato Grosso do Sul, Brasil. Cad Saúde Pública. 2001; 2(17): 323-31.

11. Pícoli RP, Carandina L, Ribas DLB. Saúde Materno-infantil e nutrição de crianças Kaiowá e Guarani, Área Indígena de Caarapó, Mato Grosso do Sul, Brasil. Cad. Saúde Pública; 2006; 22(1): 223-227.

12. Pícoli RP, Carandina L, Ribas DLB. Hipoacusy Prevalence in Kaiowá and Guarani indigenous children. Rev. Bras. Saúde Matern. Infant. 2006; 6(2): 69-174.

13. Brand A, Pícoli RP. Mortalidade infantil entre os Kaiowá e Guarani de Mato Grosso do Sul. In: Ricardo B, Ricardo F org. Povos Indígenas no Brasil 2001/2005. São Paulo: Instituto Socioambiental; 2006. p. 795-98.

14. Thompson P. A voz do passado: a história oral. Rio de Janeiro: Paz e Terra; 1992.

15. WHO (World Health Organization). A manual for the treatment of diarrhea for use by physicians and other senior health workers. Geneva: World Health Organization (WHO/CDD/SER/80.2 Rev. 2). 1984.
16. Oliveira RC. Ação indigenista, eticidade e o diálogo interétnico. Estudos Avançados. 2000; 14(40): 213230.

17. Laplantine F. Antropologia da doença. São Paulo: Martins; 2004.

18. Sahlins M. O "pessimismo sentimental" e a experiência etnográfica: por que a cultura não é um “objeto" em via de extinção. Mana. 1997;3(3 Pt1): 41-73.

19. Langdon EJ. A Construção sociocultural da doença e seu desafio para a prática médica. In: Baruzzi RG, Junqueira C. (org). Parque Indígena do Xingu: saúde, cultura e história. São Paulo: Terra Virgem; 2005. p. 115-34.

20. Buchillet D. A Antropologia da Doença e os Sistemas Oficiais de Saúde. In: Buchillet D (org). Medicinas Tradicionais e Medicina Ocidental na Amazônia Belém: MPEG/CNPq/SCT/CEJUP/UEP; 1991.p. 21-44.

21. Ministério da Saúde. Assistência e Controle das Doenças Diarréicas. Brasília: Ministério da Saúde; 1993.

22. Morgado P. O Pluralismo médico Wayana-Apari: a intersecção entre a tradição local e a global. Cadernos de Campo. 1994; 4(1): 41-70.

Recebido em: 03/09/2007 Modificado em:15/01/2008 Aprovado em: 20/02/2008 